This provisional PDF corresponds to the article as it appeared upon acceptance. A copyedited and fully formatted version will be made available soon.

The final version may contain major or minor changes.

\title{
Emergently planned exclusive hub-and-spoke system in the epicenter of the first wave of COVID-19 pandemic in Italy: the experience of the largest COVID-19-free ICU hub for time-dependent diseases.
}

Arturo CHIEREGATO, Giacomo VERONESE, Francesco CURTO, Matteo ZANIBONI, Francesca FOSSI, Fabrizio ZUMBO, Carla SCATTOLINI, Christian COMPAGNONE, Beatrice Maria ALBERTI, Camelia BACIU, Lavinia BERGESIO, Stefano M. CARENINI, Cristiana CIPOLLA, Alessandra C. FORMENTANO, Alessandro GUIDI, Francesco MASSIMO, Irene GALLUCCIO, Silvano PAGANI, Rosaria PAPARONE, Federico POZZI, Lorenzo PRESSATO, Enrica PUGNETTI, Mauro RIGANTI, Francesco RUGGIERI, Fernanda TAGLIAFERRI, Gabriele TRINCHERO, Emanuele VASSENA, Gabriele BASSI, Riccardo GIUDICI, Marco SACCHI, Osvaldo CHIARA, Elio Clemente AGOSTONI, Giacomo GRASSELLI, Roberto FUMAGALLI

Minerva Anestesiologica 2021 Jun 08

DOI: 10.23736/S0375-9393.21.15455-0

Article type: Original Paper

(C) 2021 EDIZIONI MINERVA MEDICA

Article first published online: June 8, 2021

Manuscript accepted: May 11, 2021

Manuscript revised: April 27, 2021

Manuscript received: December 11, 2020

Subscription: Information about subscribing to Minerva Medica journals is online at: http://www.minervamedica.it/en/how-to-order-journals.php

Reprints and permissions: For information about reprints and permissions send an email to: journals.dept@minervamedica.it - journals2.dept@minervamedica.it - journals6.dept@minervamedica.it 


\section{Emergently planned exclusive hub-and-spoke system in the epicenter of the first wave of COVID-19} pandemic in Italy: the experience of the largest COVID-19-free ICU hub for time-dependent diseases.

Arturo CHIEREGATO ${ }^{1 *}$, Giacomo VERONESE ${ }^{2}$, Francesco CURTO ${ }^{1}$, Matteo ZANIBONI ${ }^{1}$, Francesca FOSSI $^{1}$, Fabrizio ZUMBO ${ }^{1}$, Carla SCATTOLINI ${ }^{1}$, Christian COMPAGNONE ${ }^{1}$, Beatrice Maria ALBERTI ${ }^{1}$, Camelia BACIU ${ }^{1}$, Lavinia BERGESIO ${ }^{1}$, Stefano M. CARENINI ${ }^{1}$, Cristiana CIPOLLA ${ }^{1}$, Alessandra C. FORMENTANO $^{1}$, Alessandro GUIDI ${ }^{1}$, Francesco MASSIMO ${ }^{1}$, Irene GALLUCCIO ${ }^{1}$, Silvano PAGANI ${ }^{1}$, Rosaria PAPARONE ${ }^{1}$, Federico POZZI ${ }^{1}$, Lorenzo PRESSATO ${ }^{1}$, Enrica PUGNETTI ${ }^{1}$, Mauro RIGANTI ${ }^{1}$, Francesco RUGGIERI ${ }^{1}$, Fernanda TAGLIAFERRI ${ }^{1}$, Gabriele TRINCHERO ${ }^{1}$, Emanuele VASSENA ${ }^{1}$, Gabriele BASSI $^{3}$, Riccardo GIUDICI ${ }^{3}$, Marco SACCHI ${ }^{4,5}$, Osvaldo CHIARA ${ }^{6,7}$, Elio Clemente AGOSTONI $^{8}$, Giacomo GRASSELLI ${ }^{9,10}$, Roberto FUMAGALLI ${ }^{2,3}$

\section{Affiliations}

${ }^{1}$ Neurointensive Care Unit, ASST Grande Ospedale Metropolitano Niguarda, Milan, Italy.

${ }^{2}$ School of Medicine and Surgery, University of Milano-Bicocca, Monza, Italy.

${ }^{3}$ Department of Anesthesia and Intensive Care 1, ASST Grande Ospedale Metropolitano Niguarda, Milan, Italy.

${ }^{4}$ SOREU, ASST Grande Ospedale Metropolitano Niguarda, Milan, Italy.

${ }^{5}$ Local organ procurement organization, ASST Grande Ospedale Metropolitano Niguarda, Milan, Italy.

${ }^{6}$ School of Medicine and Surgery, University of Milan, Milan, Italy.

${ }^{7}$ Trauma Team, ASST Grande Ospedale Metropolitano Niguarda, Milan, Italy.

${ }^{8}$ Stroke Unit, ASST Grande Ospedale Metropolitano Niguarda, Milan, Italy.

${ }^{9}$ Department of Pathophysiology and Transplantation, University of Milan, Milano, Italy.

${ }^{10}$ Department of Anesthesia and Intensive Care, Fondazione IRCCS Ca' Granda Ospedale Maggiore Policlinico, Milan, Italy.

\section{Corresponding author}

Arturo Chieregato

Neurointensive Care Unit

ASST Grande Ospedale Metropolitano Niguarda

Piazza Ospedale Maggiore 3, 20162, Milan

+390264442738

arturo.chieregato@ospedaleniguarda.it 


\section{Abstract}

BACKGROUND: Lombardy was the epicenter in Italy of the first wave of COVID-19 pandemic. To face the contagion growth, from March 8 to May 8 2020, a regional law re-designed the hub-and-spoke system for time-dependent diseases to better allocate resources for COVID-19 patients.

METHODS: We report the reorganization of the major hospital in Lombardy during COVID-19 pandemic, including the rearrangement of its ICU beds to face COVID-19 pandemic and fulfill its role as extended hub for time-dependent diseases while preserving transplant activity. To highlight the impact of the emergently planned hub-and-spoke system, all patients admitted to a COVID-19-free ICU hub for trauma, neurosurgical emergencies and stroke during the two-month period were retrospectively collected and compared to 2019 cohort. Regional data on organ procurement was retrieved. Observed-to-expected (OE) in-ICU mortality ratios were computed to test the impact of the pandemic on patients affected by time-dependent diseases.

RESULTS: Dynamic changes in ICU resource allocation occurred according to local COVID-19 epidemiology/trends of patients referred for time-dependent diseases. The absolute increase of admissions for trauma, neurosurgical emergencies and stroke was roughly two-fold. Patients referred to the hub were older and characterized by more severe conditions. An increase in crude mortality was observed, though OE ratios for in-ICU mortality were not statistically different when comparing 2020 vs. 2019. An increase in local organ procurement was observed, limiting the debacle of regional transplant activity.

CONCLUSIONS: We described the effects of a regional emergently planned hub-and-spoke system for time-dependent diseases settled in the epicenter of COVID-19 pandemic in Italy.

\section{Key words}

COVID-19, hub-and-spoke, neurosurgical emergencies, stroke, trauma, organ procurement.

\section{Running title}

The impact of a COVID-19-free ICU hub for time-dependent diseases during the pandemic 


\section{What is known}

- Hub referral for time-dependent diseases has been demonstrated effective in pre-COVID-19 period.

- Few data on the effects of an urgent rearrangement in the hub-and-spoke system settled during COVID-19 pandemic for critical non-COVID-19 patients are available.

\section{What is new}

- Compared to the prepandemic period, patients referred to our hub were older and characterized by more severe conditions.

- An increase in crude mortality was observed, though the observed-to-expected in-ICU mortality ratios were not different.

- The emergently planned hub-and-spoke system limited the debacle of regional transplant activity observed during COVID-19 pandemic. 


\section{Introduction}

Lombardy was the epicenter of the first wave of coronavirus disease 2019 (COVID-19) pandemic in Italy. The regional health system response for the care of COVID-19 patients in terms of Intensive Care Units (ICU) rearrangement has been extensively described ${ }^{1,2}$. In order to face the expected COVID-19 contagion growth $^{3}$, on March 8, 2020, a regional law (decree $\left.\mathrm{n}^{\circ} \mathrm{XI} / 2906\right)^{4,5}$ designed a hub-and-spoke system for time-dependent diseases to better allocate hospitals resources for COVID-19 patients and to prevent further pandemic diffusion by defining separate pathways for patients with and without COVID-19. Three hospitals in Lombardy (Niguarda Hospital in Milano, Circolo Hospital and Macchi Foundation in Varese and Spedali Civili Hospital in Brescia) were nominated temporary hubs for major traumas, strokes and neurosurgical emergencies for the overall Lombardy population (approximately 10 million people, $16.2 \%$ of the national population ${ }^{6}$ ). Referral of patients affected by time-dependent diseases in few centers was designed to entirely relieve spokes hospitals from the acute care of critical non-COVID-19 patients. Therefore, adopting the terminology of the trauma system ${ }^{7,8}$, the designed hub-and-spoke system was "exclusive" as spoke hospitals were not involved in the care of time-dependent diseases. Of note, all the three hub hospitals also maintained the entire care process dedicated to COVID-19 patients. This regional rearrangement was active up to May 8, 2020 (two month period).

We describe the reorganization of the largest hospital in Lombardy during the first wave of the COVID-19 pandemic, including the rearrangement of its ICU beds as deemed necessary to face COVID-19 pandemic and fulfill its role as extended hub for time-dependent diseases while preserving transplant activity. A thorough examination of the resource allocation is reported with a specific focus on the experience of a neuroICU converted into the largest ICU hub for critically ill non-COVID-19 patients affected by major trauma, stroke and neurosurgical emergencies. Insights on the effects of this regional reorganization of the hub-and-spoke system for time-dependent diseases are also provided.

\section{Materials and methods}

\section{Interventions during COVID-19 pandemic}

In the prepandemic era Niguarda hospital was the largest hospital in Milan district ${ }^{9}$ (3 279944 inhabitants $\left.{ }^{6}\right)$. It was equipped with 40 operating theaters, 350 ambulatory clinics, over 70 wards, 1167 beds and all specialties, and it was a referral hospital for transplant activity, trauma, neurological and cardiovascular as well cerebrovascular emergencies. Regarding ICU facilities, before the pandemic, the hospital had 35 ICU beds: eight for trauma/surgical emergencies and general medical ICU patients, nine for neurological emergencies (neuroICU), 12 for cardiovascular emergencies and cardiac transplant activity, six for major abdominal surgeries and liver-kidney transplant activity. Specifically, the neuroICU was dedicated to the care of any kind of acute neurological disease, traumatic brain injury and spinal cord injuries, supporting patients undergoing neurosurgical and radiological interventions. In 2019 the neuroICU admitted 530 adult and 104 pediatric patients (325 [61.3\%] and 36 [34.6\%] admitted urgently, respectively). The staff included 28 nurses and 20 medical doctors. 
On February 22, 2020, two days after the first Italian confirmed case of COVID-19, the hospital administration nominated a professional group of health care specialists (so called "Crisis Unit") to coordinate hospital reorganization and beds rearrangement according to the pandemic evolution. The neuroICU was reconverted into a general ICU dedicated to all non-COVID-19 critical patients of the hospital, increasing its number of beds from nine to 11 . At that moment, the hospital had already activated and occupied 33 COVID-19 ICU beds in three reconverted ICUs, including the cardiac ICU as the hospital was not nominated hub for cardiovascular emergencies. A further COVID-19-free five-bed postsurgical ICU was preserved mostly for transplant activities ${ }^{10,11}$. After March 8, 2020 Niguarda hospital became the referral hub for major traumas, strokes and neurosurgical emergencies for 17 affiliated spoke hospitals, serving an area of 6376970 inhabitants (63.4\% of total Lombardy population). Primary access for timedependent diseases was managed by the Lombardy emergency system (AREU), without a strict adherence to geographic location but considering each hub's admission capability. The Crisis Unit increased the number of beds of the COVID-19-free hub ICU from 11 to 20, becoming the largest COVID-19-free hub ICU of the region. All elective neurosurgical and neuroradiological procedures were suspended. Medical staff remained the same (all neurointensivists), increasing work commitments by $30 \%$ of their standard. Nursing staff was increased by 23 additional untrained nurses. While the initial ICU beds for COVID-19 patients were obtained by reconverting previously existing ICU resources, from that date on no beds of the COVID-19-free ICU were converted into beds for COVID-19 patients. Nevertheless, two additional COVID-19 ICUs were opened reaching a maximum of 76 ICU beds simultaneously occupied by COVID-19 patients.

Rearrangements of both COVID-19 ICU beds (up to five COVID-ICUs) as well as COVID-19-free ICU resources during the two months is presented in Figure 1. Admission to COVID-19-free ICU was allowed only after ruling out SARS-CoV-2 through a negative nasopharyngeal swab (patients were held in a dedicated room for six hours while awaiting the results). Family visiting and interview policies were unchanged in the COVID-19-free ICU, with the policy to restrict the visit to only one relative per patient per time ${ }^{12}$. Of note, given the unprecedent situation, no proxy was systematically collected by the regional health system to test the efficiency of the emergently planned hub-and-spoke system.

\section{Statistical analysis}

ICU available beds and ICU occupied beds were recorded daily from December 29, 2019 to July 5, 2020 in order to highlight the dynamic changes in resource allocation occurred during the pandemic. All patients admitted to the COVID-19-free hub ICU for major traumas, strokes and neurosurgical emergencies during the two months serving as extended regional hub were collected and described; those admitted in the same time period of 2019 were selected as control group. All data were retrospectively obtained from the standard institutional clinical reports. Baseline characteristics of the population were tabulated using standard descriptors of central tendency and variability (mean \pm standard deviation or median and interquartile range). Differences between groups were analyzed using parametric and nonparametric tests, as appropriate. Multivariate logistic regression was performed to standardize in-ICU mortality adjusting for age, initial Glasgow Coma Scale (GCS), reactivity status of the pupils. Patients not affected by trauma, stroke and 
neurosurgical emergencies were excluded from statistical analysis in the effort to compare homogenous populations. A p-value below 0.05 was considered statistically significant. Observed-to-expected (OE) inICU mortality ratios were also computed. Additionally, the overall number of organs procured and therefore transplanted by the COVID-19-free ICU hub was collected and compared to the overall number of the organs procured and transplanted by the affiliated spokes and the other hospitals in the region before, during and immediately after the pandemic (from December, 29 to July, 5) to highlight the impact of the pandemic on regional transplant activity. Statistical analysis were performed using Data Desk (DataDesk 8.0, Ithaca) and SPSS statistical package (IBM SPSS Statistics, version 26). The study was approved by the local Ethic committee, informed consent was waived due to the retrospective nature of the study.

\section{Results}

\section{Details on resource allocation}

During the two months serving as extended regional hub, Niguarda hospital reserved 3087 ICU days for COVID-19 patients (with a maximum of 76 occupied beds), 1445 ICU days for COVID-19-free patients with trauma, stroke and neurosurgical emergencies (with a maximum of 20 available beds) and 180 ICU days for non-COVID-19 transplanted patients (with a maximum of five allocated beds).

When considering the COVID-19-free hub ICU, occupation rate trend showed a progressive increase during the observation period also when the admissions for COVID-19 patients in Lombardy ICUs were in a progressive and constant reduction. Specifically, 178 patients were consecutively admitted to the COVID19-free hub ICU (vs. 114 patients in 2019). A total of 27 patients in 2020 and 42 in 2019 were not affected by trauma, stroke and neurosurgical emergencies and were thus excluded from the analysis. The final cohorts were characterized by 151 patients in 2020 and 72 patients in 2019. During the two-month observation period the admission rate for major traumas, stroke and neurosurgical emergencies had a two-fold increase compared to 2019 (a 4.4 fold increase in stroke patients, a 2.0 fold increase in neurosurgical emergencies and a 1.9 fold increase in trauma patients).

The geographic areas from where the patients were admitted are depicted in Figure 2. As expected, there was an increase in the referral of patients from areas outside Milan in 2020 vs. 2019 (from $18.1 \%$ to 33.1\%). Back transfer to the spokes once the emergent indication for referral was solved increased in respect to the previous year. Four patients (36.4\% of those discharged outside Niguarda) were transferred outside Lombardy in regions less afflicted by the pandemic thanks to the Italian Civil Protection. Only two patients with time-dependent diseases tested positive for SARS-CoV-2 and were thus admitted to COVID-19 ICUs. No patients became SARS-CoV-2 infected during the ICU stay.

\section{Clinical management and outcomes of patients admitted for trauma, stroke and neurosurgical emergencies}

Table 1 summarizes the clinical characteristics and outcomes of patients admitted to the COVID-19-free hub ICU for trauma, stroke and neurosurgical emergencies, comparing the years 2019 and 2020. An increase in crude mortality was observed: $21.9 \%(n=33)$ vs. $12.5 \%(n=9)$ in 2019 . In 2020 patients were one decade 
older, with more comorbidities, presenting with more severe neurological conditions (lower GCS [median 11 in 2020 vs. 14 in 2019] values and more patients with bilaterally dilated unreactive pupils were reported [15\% in 2020 and 5\% in 2019]). Additionally, disease severity scores were worse in 2020. The logistic model showed a significant association with in-ICU mortality with low GCS values (0.71, CI 0.62-0.93), one pupil dilated and unreactive to light (OR 7.60, CI 1.50-40.10) as well with both pupils dilated unreactive to light (OR 12.30, CI 2.3-65.4) and increasing age (OR 1.04, CI 1.01-1.07). The accuracy in the prediction of the model was $90.6 \%$ (Hosmer and Lemeshow test, $\mathrm{p}$ value 0.576 ). The OE ratios for in-ICU mortality were not statistically different when comparing the two years, even after excluding those patients where a decision to withdraw treatment was taken. A decline of emergent surgery or procedures was probably explained by the increased rate of unsalvageable patients. The non-standardized incidence of tracheostomy remained unchanged (25.8\% in 2020 and $25.0 \%$ in 2019), while the timing of the procedure was anticipated (median, one day after admission in 2020 vs. two days after admission in 2019). Due to the reduction of high dependency beds and the higher occupancy rate of stroke units most patients were discharged to regular wards (71\% in 2020 vs. 47\% in 2019). More readmissions (albeit not statistically significant) were observed. Similarly, among the patients who died, we observed an increased rate of life-support treatment withdrawal ( $33.3 \%$ in 2020 vs. $11.1 \%$ in 2019). Of interest, an increased incidence in suicide attempts, in particular through defenestration, was observed, as extensively described in a previous report ${ }^{13}$.

\section{Details on transplant activity}

During the pandemic there was a consistent decline in organ transplantation (Figure 3) activity in Lombardy. During the two-month observation period the number of transplanted organs ( $n=62)$ was halved compared to 2019 ( $n=125$ ). Conversely, the raised mortality of patients referred to our COVID-19-free hub ICU led to an increase in local organ procurement activity, accounting for 59.7\% (37/62) of all the organs transplanted in Lombardy. Indeed, 13 of the 33 patients who died (39.4\%) became organ donors (39.4\%), accounting for $61.1 \%$ (total $\mathrm{n}=18$ ) of all donors in Lombardy during the study period. The average number of 5.5 donors per month observed during the pandemic outbreak was roughly four times higher than the average value of 1.4 recorded in the years 2011-2019. In the same time-period in 2019 the overall number of regional donors was 38 , of whom only 4 (10.5\%) died in Niguarda. A parallel decline in organ procurement in the spoke hospitals was observed (Figure 3), highlighting the effectiveness of this regional reorganization. Overall, in the twomonth period, one heart transplant and 16 liver transplants were performed and admitted to the COVID-19free five-bed posttransplant ICU (heart transplants were six in 2019 and liver transplants were 18 in 2020).

\section{Discussion}

The hub-and-spoke system created during the COVID-19 pandemic emergency was associated with increased admission of patients with trauma, stroke and neurosurgical emergencies to the neuroICU of our hospital converted into the largest COVID-19-free hub ICU of Lombardy. Compared to the previous year, the increase was roughly two-fold. This result demonstrates that the referral process was efficiently applied by the regional emergency health system after the institutional disposition. Patients referred to the hub were 
older and characterized by more severe neurological and general conditions and in whom the final benefit of treatments remained uncertain. The widening of commonly used criteria guiding patients' referral to the hub might be explained by the shift from the traditional inclusive to an exclusive hub-and-spoke system. Indeed, the spoke centers were excluded from the acute care of non-COVID-19 critically-ill patients, allowing them to allocate greater resources to COVID-19 patients.

One major concerns of the COVID-19-free hub ICU was to maintain the same performance indices of the center also during the pandemic emergency, in the context of previously unseen surge of demands and scarcity of medical resources ${ }^{14,15}$. As suggested above, the higher mortality observed for the referred timedependent diseases was probably due to the admission of older patients (approximately 10 years older compared to the previous year) and their higher disease burden and clinical severity. This suggests that the patients' referral to the hub was primarily achieved to spare medical resources to overwhelmed spokes afflicted by COVID-19 patients, and that less selective admission criteria were adopted. Potentially, delays in the call of the emergency services may have contributed to the observed higher patient severity at admission as suggested by some authors ${ }^{16,17}$. ICU length of stay during the observation was reduced. Specific interventions may partially explain this finding: first of all, thanks to the interruption of the elective procedures, higher number of beds were available in the regular wards. The observed attitude towards an early tracheostomy may have also contributed ${ }^{18}$. Additionally, the higher rate of treatment withdrawal may have also played a role. However, the OE ratios for in-ICU mortality suggested that criteria for treatment withdrawal were not applied differently compared to the prepandemic period.

Due to the possibility to trace the transplant activity at a regional level, cross-sectional observation of the trend of organs supplied for transplantation can be considered a tangible indicator of the effectiveness of the emergently planned hub-and-spoke system. As previously shown in USA and France ${ }^{19}$, a fall in organ procurement was confirmed during the pandemic also in Lombardy. Several reasons may be hypothesized, among them a reduction of road accidents, a lower number of patient presentation to the hospital ${ }^{20}$ and an unintentional or intentional restriction in the system of transplantation. Whatever the reasons, we provided evidence that the contribution of a COVID-19-free hub ICU stemmed the debacle of transplant activity observed during the pandemic in Lombardy ${ }^{11}$, perhaps allowing the spoke hospitals to devote more resources to the care of COVID-19 patients. The admission of a higher number of unsalvageable patients due to the widening of referral criteria may have played a role in maintaining an effective organ procurement activity which was probably unlikely to occur if the patients were not referred to the hub. For sure, the presence of health care personnel trained in organ procurement played a key role in enforcing this activity. The comparison between the trend of ICU admission of COVID-19 patients in Lombardy and of patients entering the COVID-19-free hub ICU may also support the idea that in the decreasing phase of the pandemic the emergently planned hub-and-spoke system might have contributed to the restoration of "normal care processes" in the spoke hospitals.

Overall, these results showed how a major hospital settled in the epicenter of the pandemic outbreak was able to accomplish the "nearly impossible mission" of granting adequate care for both COVID-19 patients and for patients affected by time-dependent diseases, while partially preserving the organ procurement 
system. Based on this data, we can infer some main reasons for this result: first, a prepandemic constant application of a clinical method based on collaborative and repetitive assessment of patient's objective and subjective components, as well as the early identification of a personalized plan for each patient, simplified patients' care-pathways even in this unprecedent circumstances ${ }^{21}$. Second, the rate of increase in the number of critical COVID-19 cases in the Milan area was slower than in other areas of Lombardy, giving enough time to reorganize the hospital. Third, the "Crisis Unit", observing the local epidemic epidemiology daily, lead to a progressive opening of new COVID-19 ICU beds not at the expense of resources allocated for nonCOVID-19 patients. The dynamic and fluid allocation of resources, mostly based on local pandemic epidemiology/trends of centralization, was in our opinion the key element to face the surge of both COVID19 cases and of patients referred for time-dependent diseases. Moreover, the prepandemic availability of efficient trauma ${ }^{22}$, neurosurgical ${ }^{23,}{ }^{24}$, neuroradiological, stroke ${ }^{25}$, transplantation ${ }^{11}$ facilities, as well as the expertise in the care of time-dependent diseases, facilitated the emergent management of the situation. Finally, the involvement in COVID-19-free hub-ICU of professionals previously trained in organ procurement was able to preserve, even in resource-limited circumstances, the attention for the potential donors.

\section{Conclusions}

In conclusion, we described the effects of a regional emergently planned hub-and-spoke system for timedependent diseases settled in the epicenter of the first wave of COVID-19 pandemic in Italy. Despite the limits of the study, this rearrangement seemed effective as demonstrated by the net increase of patients referred to our hub hospital, though characterized by older age, higher disease burden and raised crude mortality. An increase in local organ procurement activity, limiting the debacle of transplant activity, was the major tangible benefit of this regional reassessment. 


\section{Acknowledgements}

We acknowledge Franca Spotti and all the nurses of the Neurointensive Care Unit of the ASST Grande Ospedale Metropolitano Niguarda for their remarkable efforts in providing care for the critically ill patients. We acknowledge the following members of the COVID-19 Crisis Unit of the ASST Grande Ospedale Metropolitano Niguarda: Marco Bosio, MD (ASST Grande Ospedale Metropolitano Niguarda), Mauro Moreno, MD (ASST Grande Ospedale Metropolitano Niguarda), Simona Giroldi (ASST Grande Ospedale Metropolitano Niguarda), Matteo Corradin, MD (ASST Grande Ospedale Metropolitano Niguarda), Gaetano Elli, MD (ASST Grande Ospedale Metropolitano Niguarda), Angela Lolli, MD (ASST Grande Ospedale Metropolitano Niguarda), Giuseppa Bellavia (ASST Grande Ospedale Metropolitano Niguarda), Simona Giroldi (ASST Grande Ospedale Metropolitano Niguarda), Roberto Fumagalli, MD (ASST Grande Ospedale Metropolitano Niguarda), Oscar Massimiliano Epis, MD (ASST Grande Ospedale Metropolitano Niguarda), Andrea Bellone, MD (ASST Grande Ospedale Metropolitano Niguarda), Federico Perno, MD (ASST Grande Ospedale Metropolitano Niguarda), Massimo Puoti, MD (ASST Grande Ospedale Metropolitano Niguarda), Giampaolo Micheloni, MD (ASST Grande Ospedale Metropolitano Niguarda), Chiara Vismara, MD (ASST Grande Ospedale Metropolitano Niguarda), Marco Ciboldi (ASST Grande Ospedale Metropolitano Niguarda). We acknowledge Michaela Bertuzzi (ASST Grande Ospedale Metropolitano Niguarda) for providing administrative data of patients flow. We acknowledge Alberto Zanella, MD (Fondazione IRCCS $\mathrm{Ca}$ ' Granda Ospedale Maggiore Policlinico, Milan) for retrieving data on the admissions of patients in the COVID-19 Lombardy ICU Network. We acknowledge the residents Simone Checchi, Riccardo Legler, Fabio Pavan, Elisabetta Zago, Ruggiero Zipeto who highly supported the senior doctors of the Neurointensive Care Unit. We acknowledge Fabiana Villa, MD who supported data collection. We acknowledge Maurizio Migliari, MD (AREU) and Filippo Bernasconi, MD (ASST Grande Ospedale Metropolitano Niguarda) for their contribution in collecting data regarding the out-of-hospital management of the patients. We acknowledge Marco Cenzato, MD (ASST Grande Ospedale Metropolitano Niguarda) and Edoardo Boccardi, MD (ASST Grande Ospedale Metropolitano Niguarda) for their remarkable efforts in providing care to the critically ill patients affected by acute cerebrovascular diseases and trauma. We acknowledge Elisabetta Masturzo, MD (ASST Grande Ospedale Metropolitano Niguarda) from the hospital transplant procurement management for her continuous support. We thank Dario Winterton for contributing to the English revision of the manuscript. None of them were compensated for the role in the study. 


\section{Author contributions}

Concept and design: Arturo Chieregato; Acquisition, analysis, or interpretation of data: Arturo Chieregato, Francesco Curto, Christian Compagnone, Beatrice Maria Alberti, Camelia Baciu, Lavinia Bergesio, Stefano M. Carenini, Giorgio Chevallard, Cristiana Cipolla, Carmen A. Formentano, Francesca Fossi, Alessandro Guidi, Francesco Massimo, Irene Galluccio, Silvano Pagani, Rosaria Paparone, Federico Pozzi, Enrica Pugnetti, Lorenzo Pressato, Maurizio Riganti, Francesco Ruggieri, Carla Scattolini, Fernanda Tagliaferri, Gabriele Trinchero, Emanuele Vassena, Giacomo Veronese, Matteo Zaniboni, Fabrizio Zumbo, Marco Sacchi, Riccardo Giudici, Gabriele Bassi, Osvaldo Chiara; Drafting of the manuscript: Arturo Chieregato, Giacomo Veronese, Francesco Curto, Elio Clemente Agostoni; Critical revision of the manuscript for important intellectual content: Arturo Chieregato, Francesco Curto, Giacomo Veronese, Giacomo Grasselli; Statistical analysis: Arturo Chieregato; Supervision: Roberto Fumagalli. All authors read and approved the final version of the manuscript.

\section{Conflicts of interest}

None. The authors certify that there is no conflict of interest with any financial organization regarding the material discussed in the manuscript.

\section{Funding}

The authors report no funding. 


\begin{tabular}{|c|c|c|c|}
\hline & $\begin{array}{c}2019 \\
\begin{array}{c}\text { From March } 8 \text { to May } 8 \\
(\text { n. } 72)\end{array} \\
\end{array}$ & $\begin{array}{c}2020 \\
\begin{array}{c}\text { From March } 8 \text { to May } 8 \\
(n .151)\end{array} \\
\end{array}$ & p value \\
\hline \multicolumn{4}{|l|}{ Demographics } \\
\hline Male, $\mathrm{n}(\%)$ & $42(58.3)$ & $90(59.6)$ & 0.8569 \\
\hline Age, years, mean (SD) & $49.7(20.0)$ & $58.3(17.6)$ & 0.0012 \\
\hline \multicolumn{4}{|l|}{ Severity upon admission } \\
\hline Apache chronic & & & 0.0013 \\
\hline Health, n (\%) & $25(48.6)$ & $36(23.8)$ & \\
\hline Minor disease, $\mathrm{n}(\%)$ & $24(33.3)$ & $82(54.3)$ & \\
\hline Major disease, $\mathrm{n}(\%)$ & $12(16.7)$ & $25(16.6)$ & \\
\hline Dependent, n (\%) & $1(1.4)$ & $8(5.3)$ & \\
\hline GCS post stabilization, median (IQR) & $14(6)$ & $11(8)$ & 0.0220 \\
\hline Pupils & & & 0.6808 \\
\hline Normal, $\mathrm{n}(\%)$ & $63(87.5)$ & $130(86.1)$ & \\
\hline One pupil dilated unreactive, $\mathrm{n}(\%)$ & $4(5.6)$ & $6(4.0)$ & \\
\hline Both pupils dilated unreactive, $\mathrm{n}(\%)$ & $5(6.9)$ & $15(9.9)$ & \\
\hline Both pupils dilated and GCS $3 / 4, \mathrm{n}(\%)$ & $3(4.2)$ & $14(9.3)$ & 0.1792 \\
\hline SAPS II, mean (SD) & $31.8(19.1)$ & $35.9(17.3)$ & 0.1187 \\
\hline SOFA, mean (SD) & $4.3(3.5)$ & $5.5(3.5)$ & 0.0169 \\
\hline \multicolumn{4}{|l|}{ Logistic data } \\
\hline Area of the event & & & 0.0695 \\
\hline Milan city and surroundings, $\mathrm{n}(\%)$ & $44(61.1)$ & $83(55)$ & \\
\hline Niguarda spokes, n (\%) & $13(18.1)$ & $50(33.1)$ & \\
\hline Other regional hubs, $\mathrm{n}(\%)$ & $12(16.7)$ & $17(11.3)$ & \\
\hline Outside Lombardy, n (\%) & $3(4.2)$ & $1(0.7)$ & \\
\hline \multicolumn{4}{|l|}{ Time-dependent diseases } \\
\hline \multicolumn{4}{|l|}{ Trauma } \\
\hline Overall, n (\%) & $29 / 72(40.3)$ & $54 / 151(35.8)$ & \\
\hline Moderate to severe TBI, n (\%) & $6 / 29(20.6)$ & $27 / 54(50)$ & \\
\hline Isolated spinal cord injury, $\mathrm{n}(\%)$ & $2 / 29(6.9)$ & $1 / 54(1.8)$ & \\
\hline Attempted suicide, $\mathrm{n}(\%)$ & $2 / 29(10.3)$ & $17 / 54(31.5)$ & 0.0318 \\
\hline \multicolumn{4}{|l|}{ Neurosurgical emergencies } \\
\hline Overall, n (\%) & $38 / 72(52.8)$ & 75/151 (49.7) & \\
\hline ICH including AVM, n (\%) & $11 / 38(28.9)$ & $25 / 75(33.3)$ & \\
\hline SAH and surgery for aneurysm, $\mathrm{n}(\%)$ & $15 / 38(39.5)$ & $21 / 75(28)$ & \\
\hline Pediatric hydrocephalus, $\mathrm{n}(\%)$ & $2 / 38(5.3)$ & $0 / 75(0)$ & \\
\hline Adult hydrocephalus, $\mathrm{n}(\%)$ & $1 / 38(2.6)$ & $2 / 75(2.7)$ & \\
\hline Tumors, n (\%) & $8 / 38(21.1)$ & $12 / 75(16)$ & \\
\hline Non traumatic spinal cord emergencies, $\mathrm{n}(\%)$ & $0 / 38(0.0)$ & $6 / 75(6.0)$ & \\
\hline Other neurosurgical/neurological diseases, $\mathrm{n}(\%)$ & $1 / 38(2.6)$ & $9 / 75(16)$ & \\
\hline Ischemic stroke, n (\%) & $5 / 72(6.9)$ & $22 / 151(14.6)$ & \\
\hline \multicolumn{4}{|l|}{ Procedures } \\
\hline Emergent surgery or radiological procedure, $\mathrm{n}(\%)$ & $48(66.7)$ & $88(58.3)$ & 0.0560 \\
\hline Non-deferable elective surgery or radiological procedure, $\mathrm{n}(\%)$ & $11(15.3)$ & $14(9.3)$ & \\
\hline None, $\mathrm{n}(\%)$ & $13(18.1)$ & $49(32.5)$ & \\
\hline Temporary tracheostomy, $\mathrm{n}(\%)$ & $18(25)$ & $39(25.8)$ & 0.8946 \\
\hline Timing of tracheostomy, days after admission, median (IQR) & $2(2)$ & $1(1)$ & 0.0931 \\
\hline \multicolumn{4}{|l|}{ Outcome } \\
\hline LOS, days, median (IQR) & $5(7.5)$ & $3(5.7)$ & 0.0789 \\
\hline Observed in-ICU death, n (\%) & $9(12.5)$ & $33(21.9)$ & 0.0948 \\
\hline Expected in-ICU death, n (\%) & $10(13.8)$ & $32(21.1)$ & \\
\hline Withdrawal of treatment, $\mathrm{n}(\%)$ & $1 / 9(11.1)$ & $11 / 33(33.3)$ & 0.0597 \\
\hline Withdrawal of treatment patients LOS, median (IQR) & 9 & $4(5.5)$ & NA \\
\hline OE ratio for in-ICU death $(95 \% \mathrm{CI})$ & $0.87(0.26-1.48)$ & $1.04(0.69-1.39)$ & \\
\hline OE ratio for in-ICU death excluding withdrawal of treatment $(95 \% \mathrm{CI})$ & $0.90(0.20-1.60)$ & $1.05(0.57-1.52)$ & \\
\hline Organ donors (brain dead), $\mathrm{n}(\%)$ & $4 / 9(44.4)$ & $13 / 33(39.4)$ & 0.4217 \\
\hline \multicolumn{4}{|l|}{ Disposition } \\
\hline Discharge in the hospital, $\mathrm{n}(\%)$ & $57 / 72(79.2)$ & $107 / 151(70.1)$ & 0.0108 \\
\hline Critical care or subintensive unit, $\mathrm{n}(\%)$ & $20(35.1)$ & $22(20.6)$ & \\
\hline Regular ward, n (\%) & $27(47.4)$ & $76(71)$ & \\
\hline Stroke unit, $\mathrm{n}(\%)$ & $10(17.5)$ & $9(8.4)$ & \\
\hline Readmission, n (\%) & $2(2.3)$ & $7(4.6)$ & 0.72 \\
\hline Discharged to another hospital, $\mathrm{n}(\%)$ & $6 / 72(8.3)$ & $11 / 118(9.3)$ & \\
\hline LOS, days, median (IQR) & $8(5)$ & $6(4.2)$ & 0.8141 \\
\hline By means of Italian Civil Protection, $\mathrm{n}(\%)$ & NA & $4 / 11(36.4)$ & NA \\
\hline
\end{tabular}

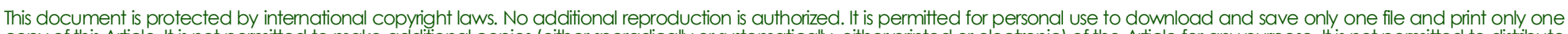

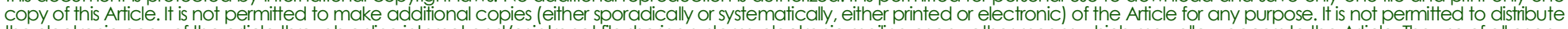

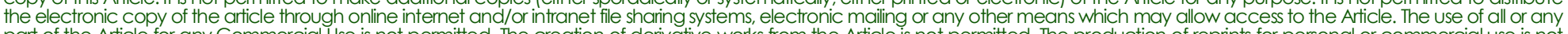

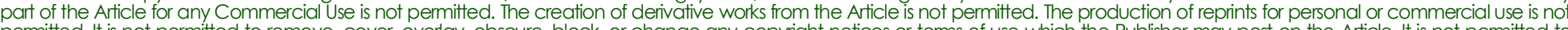

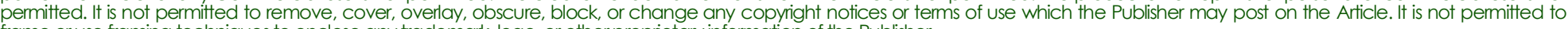
frame or use framing techniques to enclose any trademark, logo, or other proprietary information of the Publisher. 
Table 1. Characteristcs and outcome of patients admitted to Niguarda ICUs (Milan, Italy) for timedependent diseases (major traumas, strokes and neurosurgical emergencies), a comparison between 2019 and 2020.

Abbreviations: SD, santandard deviation; GCS, Glasgow Coma Scale; IQR, interquartile range; SAPS II, simplified acute physiology score; SOFA, sequential organ failure assessment score; TBI, traumatic brain injury; ICH, intraparenchymal hemorrhage; AVM, arterovenous malformation; SAH, subarachnoid hemorrhage; LOS, lenght of stay; ICU; intensive care unit; NA, not assessed. 


\section{Figure legends}

Figure 1. The graph shows the day by day rearrangement of Niguarda ICU beds (histogram) and highlights the trends in the occupied ICU beds (lines). The pre-pandemic 35 COVID-19-free ICU beds (blue histogram) progressively left the place to COVID-19 beds (green histogram) with the opening of 5 COVID-19 ICUs. Each step in the green histogram represents an opening (in the ascending slope) or a closure (in the descending one) of a COVID-19 ICU. Initially, only 11 beds for critical non-COVID-19 patients were maintained in the hospital, increased up to 20 beds when the hospital was nominated regional hub for trauma, stroke and neurosurgical emergencies (yellow histogram). Additional 5 beds for post-transplant activity (orange histogram) were preserved. The dynamic and fluid allocation of resources, mostly based on the observed daily trends of ICU occupied beds was the key element that allowed to face the double emergency of the surge in the number of both COVID-19 cases and of those affected by time-dependent diseases. It can also be appreciated that the resources for time-dependent diseases, once doubled, were no more reduced by the need to allocate facilities to COVID-19 patients.

Figure 2. The figure reports the administrative map of Lombardy and shows from where the patients were admitted to the neuroICU of Niguarda hospital in 2019 (from March 8 to May 8) and in 2020 during the institution of an emergently planned hub and spoke system settled during the first wave of COVID-19 pandemic in Italy.

Figure 3. In Panel A the fall of transplanted organs in relation to COVID-19 pandemic trend in Lombardy (green line) can be appreciated. During the nadir of the organs transplanted in Lombardy, the COVID-19free ICU hub (red bars) supported most of the regional organ procurement activity thanks to its function as regional hub. Panel B shows the cumulative trends of the transplanted organs provided by the COVID-19free hub ICU of Niguarda compared to those procured by the 17 affiliated spokes (reported on a weekly basis). It is possible to appreciate the increase of the organs procured by Niguarda from March, 8 (red lines) while a nearly plateau shape can be observed in the cumulative frequency of the organs procured by the spokes (blue line). Dashed lines represent the start (March 8) and the end (May 8) of the period as regional hub for major traumas, strokes and neurosurgical emergencies. 


\section{References}

1. Grasselli G, Pesenti A, Cecconi M. Critical Care Utilization for the COVID-19 Outbreak in Lombardy, Italy: Early Experience and Forecast During an Emergency Response. Jama 2020;323:1545-6.

2. Carenzo L, Costantini E, Greco M, Barra FL, Rendiniello V, Mainetti M, et al. Hospital surge capacity in a tertiary emergency referral centre during the COVID-19 outbreak in Italy. Anaesthesia 2020;75:928-34.

3. Remuzzi A, Remuzzi G. COVID-19 and Italy: what next? Lancet 2020;395:1225-8.

4. Regione Lombardia. INDIRIZZI PER L'ORGANIZZAZIONE DELLE ATTIVITÀ SANITARIE IN RELAZIONE ALL'ANDAMENTO DELL'EPIDEMIA DA COVID 19. 2020 [Internet]. Available from: https://www.regione.lombardia.it/wps/wcm/connect/0409d41a-e474-49cd-af65-

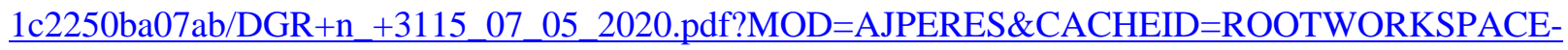
0409d41a-e474-49cd-af65-1c2250ba07ab-n8eAvAAhttp://dati.istat.it/Index.aspx?QueryId=18548. [cited 2021, Mar 3].

5. Regione Lombardia. ULTERIORI DETERMINAZIONI IN ORDINE ALL'EMERGENZA EPIDEMIOLOGICA DA COVID - 19. 2020 [Internet]. Available from: https://www.regione.lombardia.it/wps/wcm/connect/5e0deec4-caca-409c-825b25f781d8756c/DGR+2906+8+marzo+2020.pdf?MOD=AJPERES\&CACHEID=ROOTWORKSPACE5e0deec4-caca-409c-825b-25f781d8756c-n2.vCsc. [cited 2021, Mar 3].

6. Italian National Institute of Statistics. Popolazione residente al $1^{\circ}$ gennaio in Lombardia 2020. 2020 [Internet]. Available from: http://dati.istat.it/Index.aspx?QueryId=18548. [cited 2021, Mar 3].

7. Chiara O, Cimbanassi S. Organized trauma care: does volume matter and do trauma centers save lives? Curr Opin Crit Care 2003;9:510-4.

8. Chieregato A, Volpi A, Gordini G, Ventura C, Barozzi M, Caspani MLR, et al. How health service delivery guides the allocation of major trauma patients in the intensive care units of the inclusive (hub and spoke) trauma system of the Emilia Romagna Region (Italy). A cross-sectional study. BMJ Open 2017;7:e016415.

9. Ospedale Niguarda. Cura, insegnamento, ricerca. La nostra mission da oltre 80 anni. 2020 [Internet]. Available from: https://www.ospedaleniguarda.it/chi-siamo/storia-e-futuro [cited 2021, Mar 3].

10. Nord Italian Transplant Program. 2020 [Internet]. Available from:

https://www.policlinico.mi.it/AMM/nitp/area_paziente/nitp/chi_siamo.html [cited 2021, Mar 3].

11. Lauterio A, De Carlis R, Belli L, Fumagalli R, De Carlis L. How to guarantee liver transplantation in the north of Italy during the COVID-19 pandemic: A sound transplant protection strategy. Transpl Int 2020;33:969-70.

12. Chieregato A, Paci G, Portolani L, Ravaldini M, Fabbri C, Martino C, et al. Satisfaction of patients' next of kin in a 'Hub \& Spoke' ICU network. Anaesthesia 2014;69:1117-26.

13. Chevallard G, Veronese G, Giudici R, Pressato L, Pozzi F, Compagnone C, et al. Facing increased suicide attempts during COVID-19 pandemic lockdown: the experience from the major trauma center in Lombardy, Italy. Minerva Anestesiol 2020. [Epub ahead of print]. 
14. Nacoti M, Ciocca A, Giupponi A, Brambillasca P, Lussana F, MD, Pisano M, et al. At the Epicenter of the Covid-19 Pandemic and Humanitarian Crises in Italy: Changing Perspectives on Preparation and Mitigation. NEJM Catal Innov Care Deliv 2020;21(10).

15. Munari M, De Cassai A, Casartelli Liviero M, Zanatta P, Martin MA, Soragni A, et al. SARS-CoV-2 pandemic impact on traumatic brain injury epidemiology: an overview of the Veneto region. Minerva Anestesiol 2020. [Epub ahead of print].

16. Tartara F, Cofano F, Zenga F, Boeris D, Garbossa D, Cenzato M. Are we forgetting non-COVID-19related diseases during lockdown? Acta Neurochir (Wien) 2020;162:1501.

17. Maringe C, Spicer J, Morris M, Purushotham A, Nolte E, Sullivan R, et al. The impact of the COVID-19 pandemic on cancer deaths due to delays in diagnosis in England, UK: a national, population-based, modelling study. Lancet Oncol 2020;21:1023-34.

18. Andriolo BN, Andriolo RB, Saconato H, Atallah Á N, Valente O. Early versus late tracheostomy for critically ill patients. Cochrane Database Syst Rev 2015;1:Cd007271.

19. Loupy A, Aubert O, Reese PP, Bastien O, Bayer F, Jacquelinet C. Organ procurement and transplantation during the COVID-19 pandemic. Lancet 2020;395:e95-e6.

20. Uchino K, Kolikonda MK, Brown D, Kovi S, Collins D, Khawaja Z, et al. Decline in Stroke Presentations During COVID-19 Surge. Stroke 2020;51:2544-7.

21. Weed LL. Medical records that guide and teach. N Engl J Med 1968;278:593-600.

22. Chiara O, Cimbanassi S, Andreani S, Girotti P, Pizzilli G, Vesconi S. Niguarda Trauma Team: outcome of three years of activity. Minerva Anestesiol 2008;74:11-5.

23. Cenzato M, DiMeco F, Fontanella M, Locatelli D, Servadei F. Editorial. Neurosurgery in the storm of COVID-19: suggestions from the Lombardy region, Italy (ex malo bonum). J Neurosurg 2020:1-2.

24. Giorgi PD, Villa F, Gallazzi E, Debernardi A, Schirò GR, Crisà FM, et al. The management of emergency spinal surgery during the COVID-19 pandemic in Italy. Bone Joint J 2020;102-b:671-6.

25. Agostoni E, Carolei A, Micieli G, Provinciali L, Toni D, Vidale S. The organisation of the acute ischemic stroke management: key notes of the Italian Neurological Society and of the Italian Stroke Organization. Neurol Sci 2018;39:415-22. 


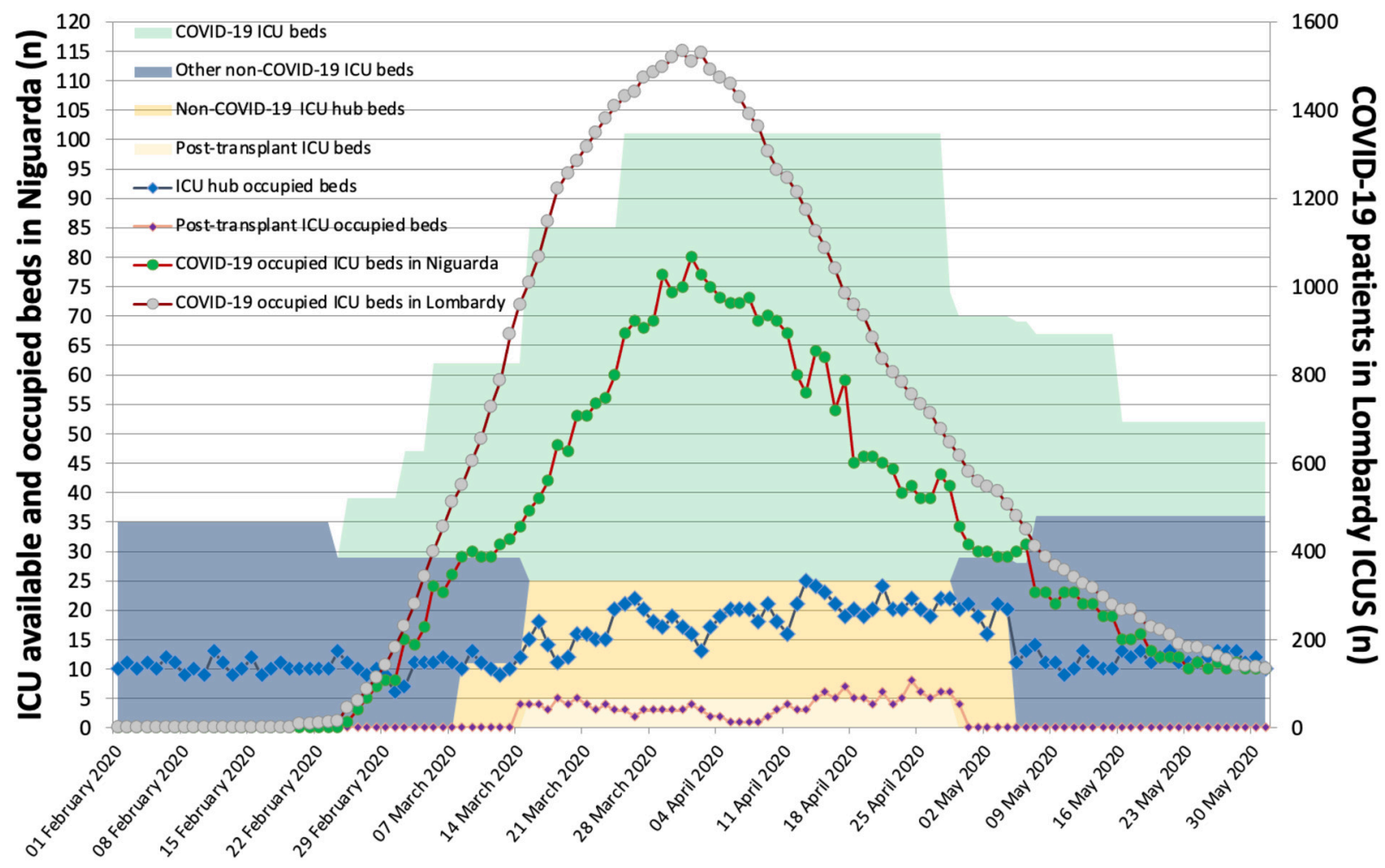

Days

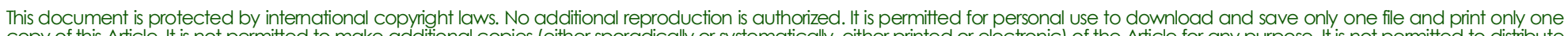

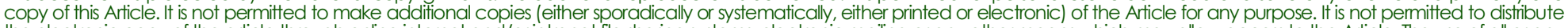

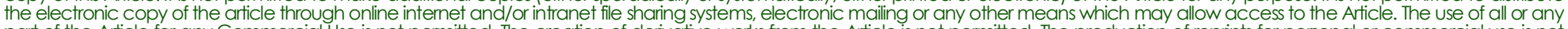

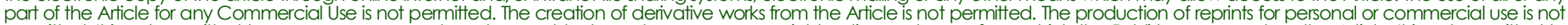

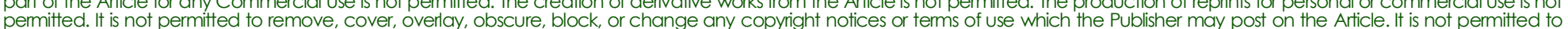
frame or use framina techniques to enclose any trademark, logo, or other proprietary information of the Publisher. 
2019

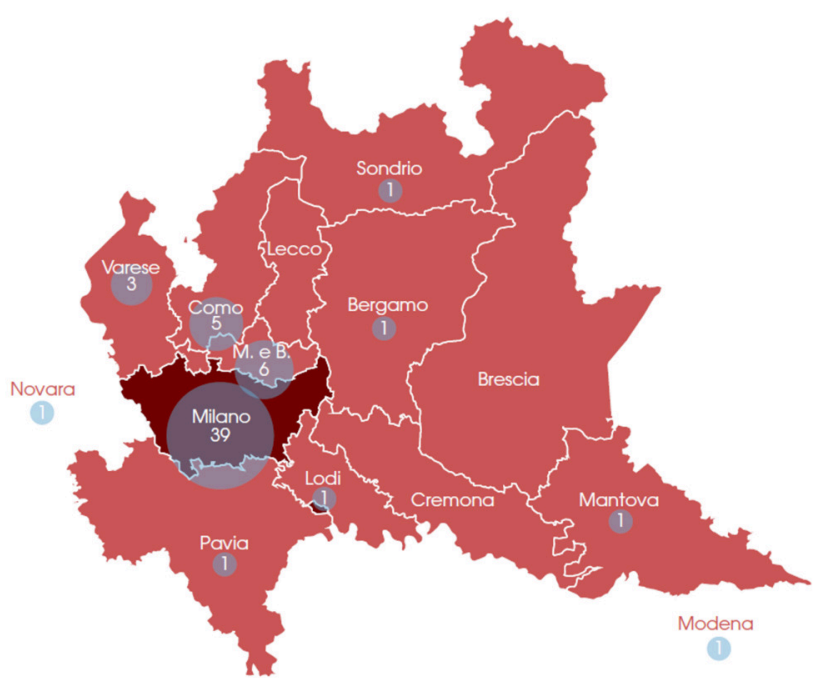

2020

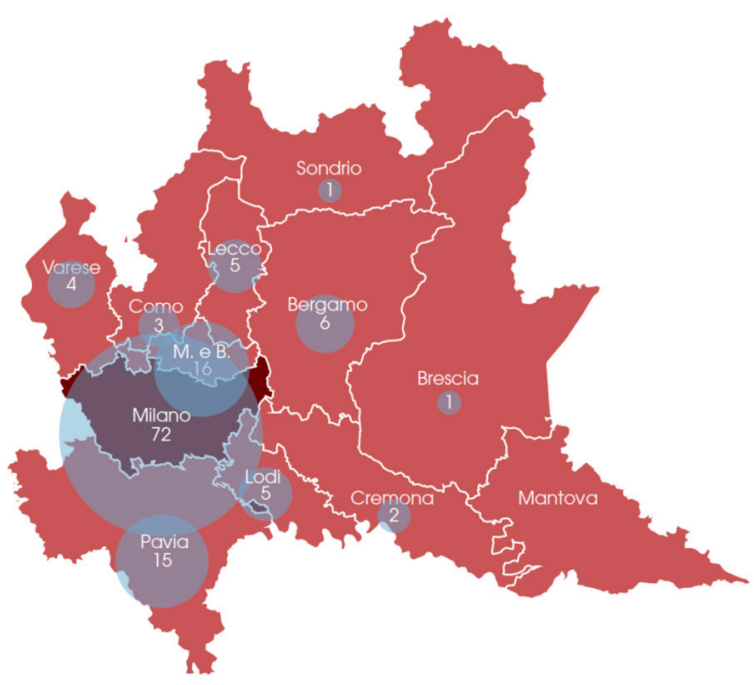



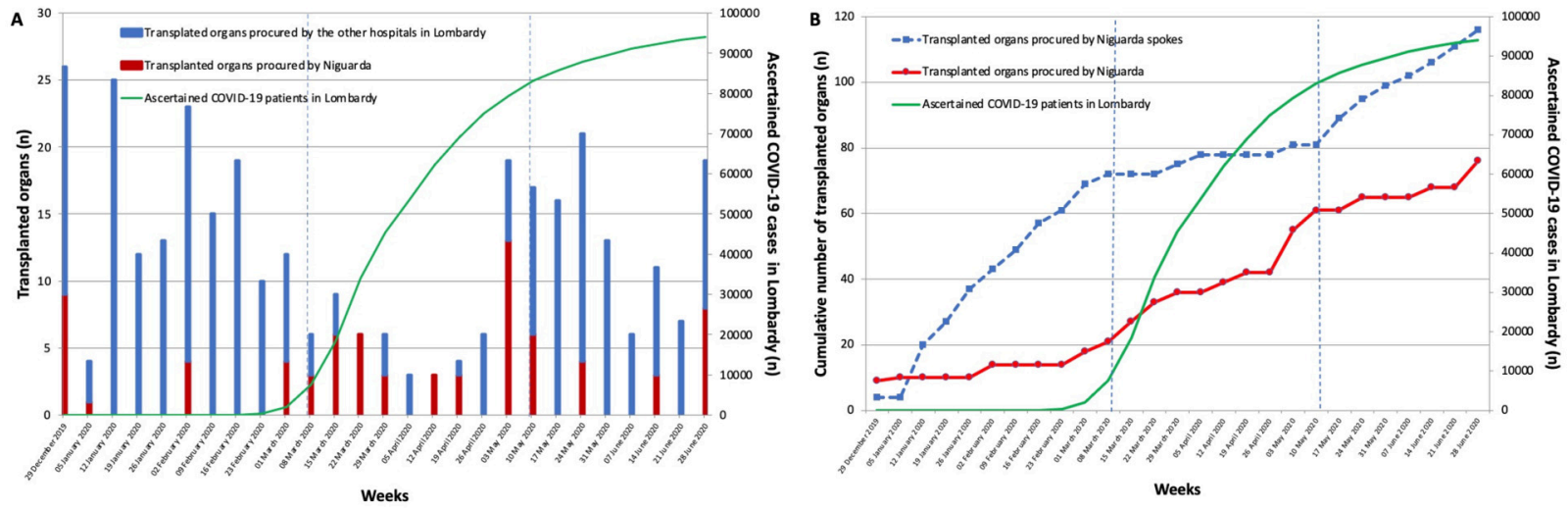

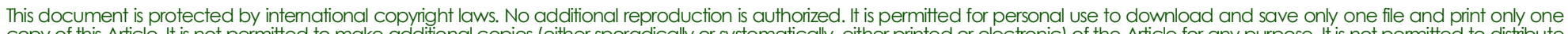

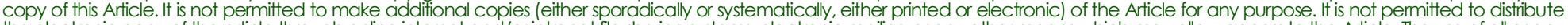

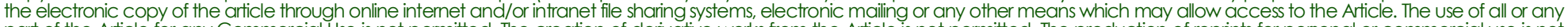

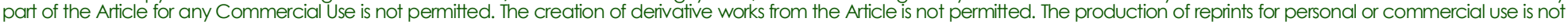

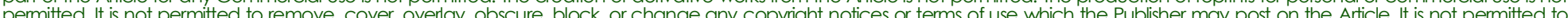

